\title{
Does sport innovation create value? The case of professional football clubs
}

\author{
Raffaele Trequattrini ${ }^{1 *}$, Manlio Del Giudice ${ }^{2}$, Benedetta Cuozzo ${ }^{1}$ and Matteo Palmaccio ${ }^{1}$
}

${ }^{*}$ Correspondence:
trekraf@tiscali.it
${ }^{1}$ Department of Economics
and Law, University
of Cassino and Southern
Lazio, Via S. Angelo, Loc.
Folcara, 03043, Cassino,
FR, Italy
Full list of author information
is available at the end of the
article

*Correspondence:

kraf@tiscali.it

and Law, University

of Cassino and Southern

Full list of author information

article

\begin{abstract}
The paper aims to analyze the role of technical-tactical innovation in creating value for professional football clubs. Over the last few years, the sector of professional sport has often been investigated to study the economic benefit generated by introducing technological innovation. From the analysis carried out on the sector of professional football, it is, however, clear that there are very few studies examining the role of technical-tactical innovation in creating value for football clubs. To fill this gap in the literature, the present article is concerned with understanding whether innovation of this kind can generate value for the football clubs in which it is used. The aim of this article is to verify whether the economic and sports results achieved by football clubs can be connected to the skill of their coaches/managers in acquiring and consolidating expertise based on innovative tactical formations. The objective of this research is to analyze the main changes brought to the football sector over the years, and then to concentrate on more recently introduced types of technical-tactical innovation.
\end{abstract}

Keywords: Innovation, Competences, Technical-tactical innovation, Coach, Football clubs, Competitive advantage

\section{Background}

\section{Introduction}

Innovation is a complex social process (Chesbrough et al. 2006) that has been argued since time. Schumpeter (1934) defined five main types of innovation: product innovation, production process innovation, innovation in organization, new market behavior and new raw materials.

Over the last few years, several other classifications of innovation have been provided. Within professional football teams, the technical-tactical innovation can be considered as production process innovation or organization innovation, in fact they represent the way to apply to players an innovative model able to become a competitive advantage over competitors.

The aim of this article is to analyze the role of technical-tactical innovation in creating value for professional football clubs.

Sport plays a central part in modern society, both socially and economically. Among the most widely practiced sports, football has gone from a sport practiced for fun or passion to being a huge business capable of generating massive economic and financial flows. 
The sector of professional sport has often been used, in recent years, as the framework for studying the economic benefit generated by introducing technological innovation (Shah 2000; Stone et al. 2001; Collins et al. 2006).

Frequent reference has been made to the introduction of technological devices, such as goal-line technology and slow motion replay, used to reduce referee errors (Liebermann et al. 2002).

From the analysis carried out on the sector of professional football, it is, however, clear that there are very few studies examining the role of technical-tactical innovation in creating value for football clubs.

To fill this gap in the literature, the present article is concerned with understanding whether innovation of this kind can generate value for the football clubs in which it is used.

According to several scholars (Baroncelli et al. 2004), technical-tactical innovation cannot be included among the sources of competitive advantage for a football club, since this kind of innovation is easy to understand and so easy to imitate.

Nevertheless, it is common knowledge that a great many football successes, at both national and club level, have been achieved through projects of technical-tactical innovation, giving the clubs where they are applied an advantage over their rivals that often lasts for several years.

Having said this, the aim of this article is to verify whether the economic and sports results achieved by football clubs can be connected to the skill of their coaches/managers in acquiring and consolidating expertise based on innovative tactical formations.

The objective of this research is to analyze the main changes brought to the football sector over the years, and then to concentrate on more recently introduced types of technical-tactical innovation.

The analysis consists first in studying the role of coaches/managers in sports exploits and then identifying the contribution made by the single coach/manager to the performance of the team.

A qualitative method was used for the research (Maylor and Blackmon 2005; Myers 2013), based on a historical analysis of the main types of technical-tactical innovation introduced in the world of football and how they affected the performance of football clubs and national teams, in terms of their sports results.

The research involved a multi-case approach (Eisenhardt 1989; Merriam 1998), with the purpose of filling the gap in the literature with respect to the possibility that innovation in technical-tactical football formations is a source of competitive advantage for football clubs in the medium and longer term.

The research made use of secondary sources (Yin 2013) and includes documents, reports, news items, journal articles in open sources, papers, scientific books and databases.

The research questions at the basis of this study are the following:

Q1 In the sector of professional football, can technical-tactical innovation lead to a competitive advantage?

Q2 How is technical-tactical innovation to be configured to ensure that, where it is introduced, it results in sustainable competitive advantage? 


\section{Coaches as managers responsible for the production function in football clubs: the role of technical-tactical innovation}

Scholars, over the years, have discussed innovation in the sports field, focusing on various aspects, such as innovation in sports equipment (Shah 2000). From the analysis of the literature, it emerges that innovation is widely considered as an element capable-in many different ways - of generating value for sports clubs. With reference to the literature on football, most contributions have been concerned with the technological aspects of innovation (Stone et al. 2001; Liebermann et al. 2002; Collins et al. 2006).

The tactics adopted by the coach/manager are one of the most significant areas of a football club that may be influenced by innovation. Nothing, however, has been said about the technical-tactical aspects of innovation in football.

As a consequence, the aim of this paper is to fill the gap concerning profitability linked to the introduction of innovative tactics. This involves investigating the effect that this kind of innovation has on the results achieved by a football team.

The results must be interpreted from a sports perspective, but we cannot ignore that sports results are at the basis of a club's economic and financial performance, given that good results generally lead to greater visibility for the club and means that its player pool is rated higher. This, in turn, points to an increased brand value and greater incoming revenue by merit of its position in more prestigious league matches (Trequattrini et al. 2015).

To answer the research questions, it is first useful to place technical-tactical innovation within the framework of the kinds of innovation that relate to any business system. It is known that the innovation of products or processes is the matter studied most widely in connection with sources of competitive advantage in companies (Schumpeter 1934, 1942).

Innovation is the greatest source of competitive advantage and is an essential requirement both for the success of the organization and for its survival (Egbu 2004; Carayannis and Campbell 2011; Del Giudice and Maggioni 2014). The economic value of innovation can often be traced to the idea that generated it or to the knowledge connected to it (Chesbrough et al. 2006).

In particular, processes connected to innovation of products or processes are linked to the great effort, whether scientific, technological, organizational, financial or commercial, undertaken to achieve a substantially improved version in terms of function or content, when compared to previous versions or to alternative methods for solving the same issues, or to the effort needed to place the improved version on the market (Dewar and Dutton 1986). It follows that a new or different game system put in place to solve organizational problems on the football pitch can be seen as an innovation to the production function of professional football clubs. According to Borland (2006), this process can be expressed through a formula in which performance is in function of a series of variables, which include the quality of the players in the team and the quality of the coach or manager. It follows that coaches/managers are the people who introduce innovation and, focusing on the aim of this research work, it is first necessary to concentrate on their role.

Football coaches/managers are usually divided into two types, the UK model and the kind present elsewhere. Outside the UK model, coaches are strictly responsible for 
managing the sports side of a football team and, in terms of innovation, are only concerned with technical-tactical aspects. In the UK model, the role is more complex, consisting in all of the above-often with other coaches involved in the sports aspects-but being above all the team manager and/or technical director. These roles are, however, not clear-cut.

The modern coach/manager has to deal with pressure from a number of stakeholders: professional players, managers, supporters and the media (Bolchover and Brady 2007). Since the managers' actions are conditioned by a variety of complex relationships, their knowledge and skill are undeniable critical (Soto-Acosta et al. 2010). Indeed, coaches/ managers need psycho-pedagogic, tactical and leadership skills.

They need psycho-pedagogic skills (Katzenbach and Smith 2005) to screen footballers, who in this environment are the human resources, to train them from a technical perspective.

Their leadership skills (Bradford and Cohen 1984; Bass 1985) give them the edge in being the team's guiding light and so achieve the group objectives.

They use technical-tactical skills (Wilson 2010) to pass on innovative tactics to their players, giving their team a competitive advantage. Dyson et al. (2004), in discussing the pedagogical aspects of sport, described a model involving the interaction of sports education, collective learning and tactical games.

Using their technical-tactical skills, coaches/managers can influence their team's performance directly, by introducing the right tactic to match the players' skills, or indirectly, by showing their ability in selecting and motivating the players likely to interpret their game strategy most correctly (Lombardi et al. 2014).

Looking at the competitive environment typical of the football sector, a technical-tactical strategy resulting in a greater number of wins would rapidly be understood and replicated by other teams (Baroncelli et al. 2004).

There are also no legal methods (Besen and Raskind 1991; Cottier and Panizzon 2004) currently available to protect this kind of innovation against being imitated by other teams, and so it cannot be considered as providing long-term competitive advantage.

It makes sense, therefore, to highlight that most great football successes occurred in the wake of a technical-tactical project that gave the team greater benefit than its competitors. In some cases, this advantage had a lasting effect.

This impact is described by Nonaka and Takeuchi (1995), who make the distinction between tacit knowledge and codified knowledge. In their view, many of the concepts passed by coaches/managers to their players are not defined in books or manuals and cannot be managed through a structured flow of communication. These notions have developed in the coaches/managers' minds and through their insight, as a result of many years of experience and practice, and are very difficult for the outsider to understand.

In light of these considerations, the objective of this study is to fill the gap in the literature concerning the relationship between technical-tactical innovation introduced in a club and its performance. The basis of the work is a historical analysis of the main types of innovation introduced into professional football at international level and the sports results that were the resulting outcome. 


\section{Results and discussion}

This paragraph contains a historical analysis of the main innovative tactical ideas, and will be used to investigate whether these ideas have had an effect on team performance.

\section{Results}

\section{The pyramid}

The first theoretical debate in the history of football goes back to the second half of the nineteenth century, with the comparison between the English 1-1-8 formation (one defender, one midfielder and eight forwards) and the Scottish 2-2-6 formation (two defenders, two midfielders and six forwards) (Fig. 1).

In the first case, the game plan relies on a single player being faster than his adversary (dribbling game), while the second case involves the players passing the ball to each other (passing game).

The first real incremental innovation was the transition from the 2-2-6 formation to the 2-3-5 "pyramid" formation (Fig. 2), successfully applied by the Blackburn Rovers, who were then able to win five consecutive FA Cups in the late nineteenth century. In the $2-3-5$ formation, playing field space is distributed more evenly among the players in a team, and for the first time, each player has a defined position.

\section{"Metodo" and "WM system"}

The second great innovation in terms of technical-tactics in football came about following a change to the rules of the game, caused by a dramatic drop in the goals scored in the English Championship during the early part of the twentieth century.

The cause of this slump was explained by the introduction of the offside rule, whereby a striker was only in the correct place if there were three players from the opposite team in front of him when he received the ball. In practice, a defender only had to move forward for the striker to be automatically offside and the game to be stopped.
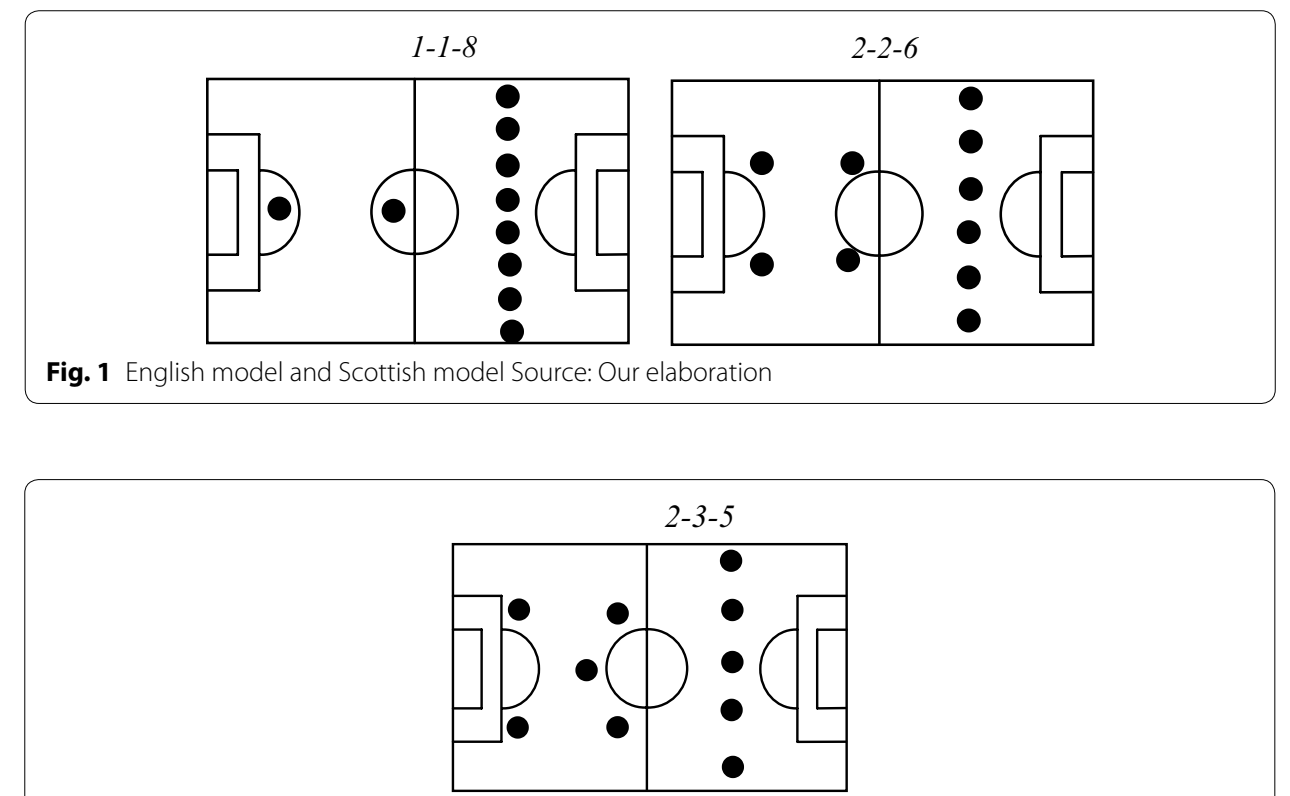

Fig. 2 The pyramid Source: Our elaboration 


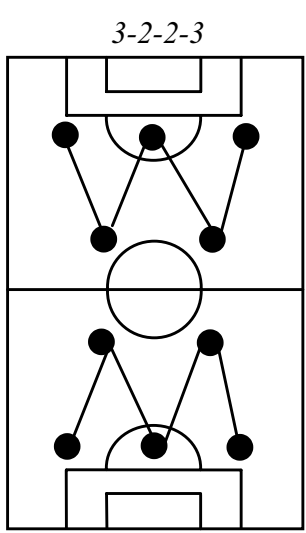

Fig. 3 The WM system Source: Our elaboration

To stop offside obstruction tactics, the rules were altered and, for the striker still to be in play, the opposite side players in front of the striker were brought down from three to two.

The change meant that an attacking game was more successful and the Arsenal manager, Herbert Chapman, tried out a new technical-tactical theory, which came to be known as the "WM system" (Fig. 3), with a three-man defense, a four-square midfield and an attack with two lateral players and one at the center, visually forming the letters WM.

With this formation, Herbert Chapman won the FA Cup in 1930 and the English Championship in 1931 and 1933.

While the change to the offside rule led to the creation of the WM system in England, in continental Europe, Vittorio Pozzi, coach of the Italian national team, devised an alternative formation that came to be known as the "Metodo" (the method), used by Italy to win the Central European International Cup in 1930 and 1935, back-to-back World Cups in 1934 and 1938 and the Olympics in 1936 (Fig. 4). The Metodo consisted a two-person defense, one with the task of marking the opposite side's center forward and the other without marking duties (right and left fullbacks); the midfield was made up of three players, two with the task of marking the opposite side's wings (halfbacks) and one being a free agent (center halfback); the attack was composed of five players, two being slightly back (right inside forward and left inside forward) and three forward (right winger, left winger and center forward).

We should stress that both methods emerged in substantially closed environments, since England started taking part in tournaments organized in mainland Europe only after the Second World, and at this point the WM system started taking over from the Metodo in all competitions.

\section{Brazil and Italy}

The first major change to the WM system was introduced by Béla Guttmann, who won the São Paulo State Championship with São Paulo in 1957 and the European Champion Clubs' Cup (European Cup) twice in a row with Benfica (1960/1961 and 1961/1962). It also inspired the formation created by Vicente Italo Feola, with which Brazil won the 


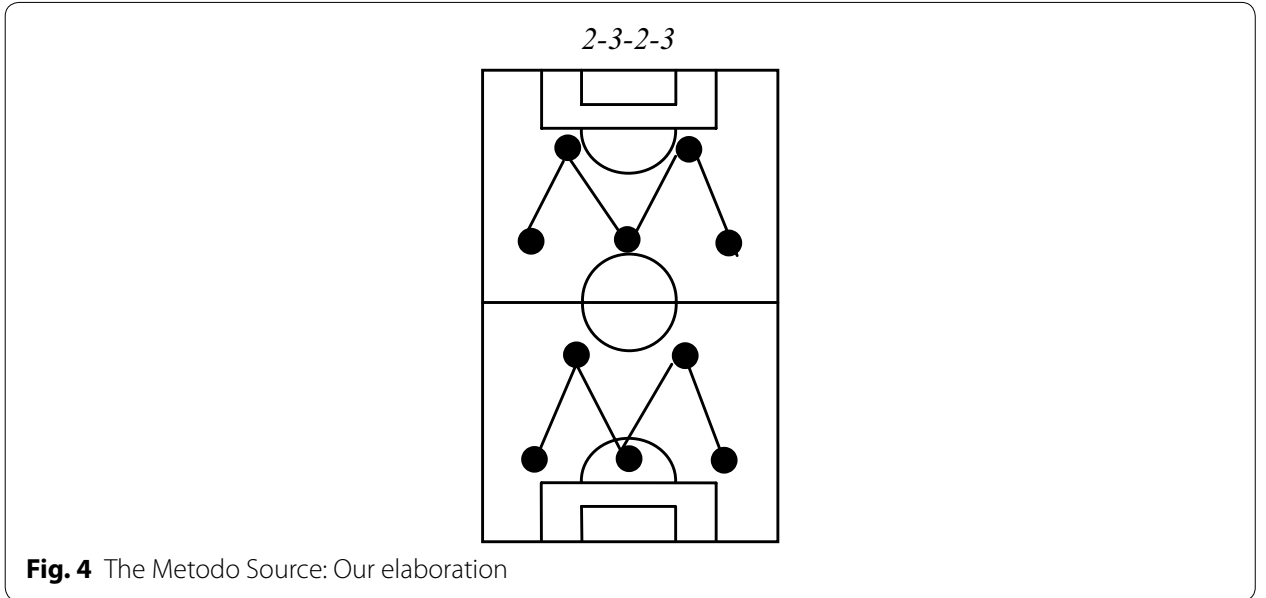

World Cup in Sweden in 1958. In this 4-2-4 formation, the defense was strengthened by the inclusion of a player taken from the midfield and included a hefty four-man attack (Fig. 5).

In reality, this formation also exploited the newly improved athleticism of players, especially as the intention was to use midfielders as additional defenders during a defensive phase and as attackers during an offensive phase.

While the 4-2-4 formation was the first important evolution of the WM system, another development, the "Catenaccio" (="deadlock", a close defense system also known as the "Chain"), in its various interpretations, was the winning formation throughout the 1960s (Fig. 6). Compared to the traditional WM system, Karl Rappan from Switzerland, universally accredited for inventing the precursor of the catenaccio formation, had the idea of removing a midfielder and placing him along the defender line; subsequently, the Italian Giuseppe Viani placed the additional defender behind the defending line, freeing him from any fixed marking duties.

Using this formation and adapting it with the skills of their players, Nereo Rocco of Italy (Fig. 7a) at AC Milan won two Italian Championships (1961/1962 and 1967/1968), two European Cups (1962/1963 and 1968/1969) and one Intercontinental Cup (1969), and Helenio Herrera of Spain (Fig. 7b) at Inter won three Italian Championships (1962/1963, 1964/1965 and 1965/1966), two European Cups (1963/1964 and 1964/1965) and two Intercontinental Cups (1964 and 1965).

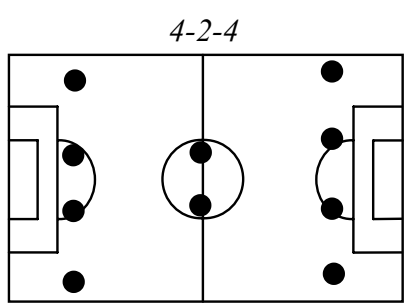

Fig. 5 4-2-4 Source: Our elaboration 


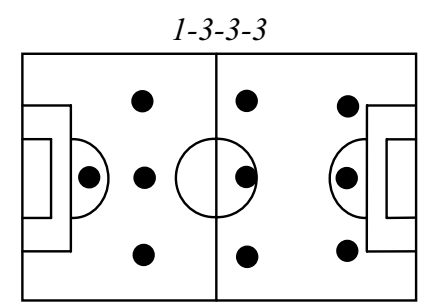

Fig. 6 The "Catenaccio" or "Chain" Source: Our elaboration

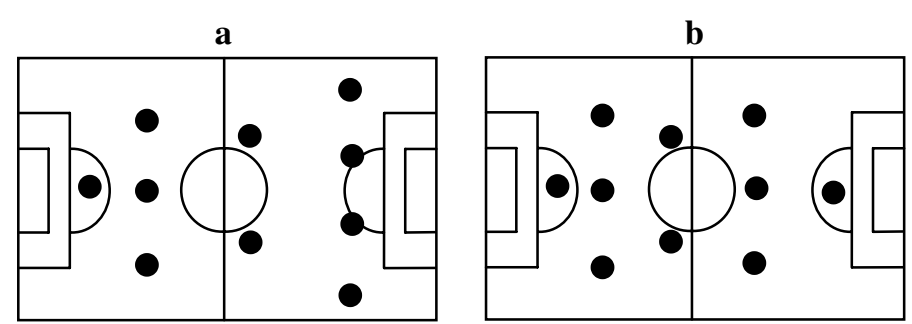

Fig. 7 a 1-3-2-4/Nereo Rocco and b 1-3-2-3-1/Helenio Herrera Source: Our elaboration

All the evidence points to this being a formation that is particularly careful in how its defense is organized and, for many years, formed the basis of the Italian School, with many Italian football clubs being able to assert themselves abroad. One particular variation was used by the Italian national football team, which won the World Cup in Spain in 1982.

\section{The revolution of "total football"}

Towards the end of the 1960s, a new "Total Football" model emerged as a reaction to the catenaccio formation. This was introduced by Marinus "Rinus" Michels, legendary manager of Ajax and the national Dutch team.

He modernized football, making the following technical-tactical changes.

(a) The purpose of a formation is not to fill the space between players on the football pitch, but to create new space through movement.

(b)Within a team, there must only be two specific positions apart from the goalkeeper: the central defender and the striker. Everyone else has to be rapid, adaptable and quickly able to switch positions.

(c) In defense, the team lined up in "zones" with no man-to-man marking. This meant that each player has an allocated zone of the pitch to control rather than another player to trail and tackle.

(d) The typical method to regain control of the ball is "pressing", which in substance means attacking the adversary in possession of the ball with at least three men.

(e) Plays starts with a 4-4-2 formation (Fig. 8), where the defense and the midfield take up parallel lines, which makes it both easy to switch positions and also to engage in offside tactics, involving a sudden collective move forwards from the backline, with the purpose of placing one or more players of the opposite team in an offside position. 


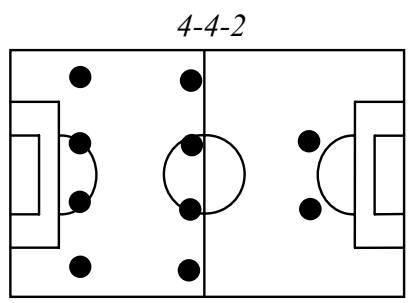

Fig. 8 4-4-2 Source: Our elaboration

Using this formation, Ajax was able to win three European Cups one after another (1970/1971, 1971/1972 and 1972/1973), Holland reached the World Cup final twice (1974 and 1978) and won the UEFA European Football Championship in 1988.

In addition, using a less dynamic version of the 4-4-2 formation developed by Michels, the English clubs Liverpool, Aston Villa and Nottingham Forest were able to win a total of seven European Cups in the 10 years between 1976 and 1986.

Another version of Rinus Michels's "Total Football" made its mark at the end of the 1980s, when Arrigo Sacchi took over at AC Milan, winning with the team, among other things, one Italian Championship 1997/1998), two European Cups (1988/1989 and 1989/1990) and two Intercontinental Cups (1989 and 1990).

The theory behind Sacchi's formation is the basic concept of the game, which substantially is a system of strategies and tactics that the coach/manager demands from the team. This idea, which must be accepted and shared by both club and team leads to a series of consequences at organizational and technical-tactical level.

At an organizational level, according to Sacchi's philosophy, the players to buy must be individuals with great human and professional qualities, who can understand the importance of placing their talent at the service of the group; in other words, they must be true stars (Marshall 1920; Rosen 1981; Simonton 1999; Anderson and Sally 2014).

At a technical-tactical level, the idea can be expressed differently according to the actual phase of the game. If the opposite team has the ball, the method to regain possession rapidly is to use zone defense alongside offside tactics and pressing. Once back in possession, the main offensive methods are fast restarts and circulating the ball rapidly often using fast vertical passes.

Sacchi had no preferred formation, although at AC Milan he often used the variation of a 4-4-2 formation which includes a diamond-shaped midfield (Fig. 9).

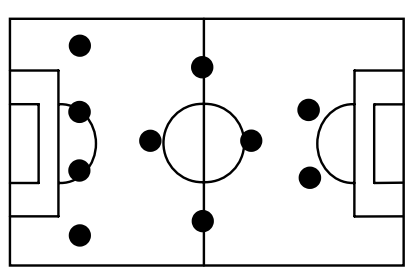

Fig. 9 4-4-2 with a diamond in midfield Source: Our elaboration 


\section{Mourinho and Guardiola}

In the mid 1990s, the introduction of three points awarded for winning a game marked the transition to more daring tactical formations, with a greater number of players taking part in the offensive action.

Many coachers/managers have been able to adjust to the three point rule, introducing incremental changes in the formation. Among these, the most significant are, in Italy, Marcello Lippi (three Italian Championships, one Champions League Cup (the previous European Cup) and one Intercontinental Cup with Juventus FC and a World Cup with the Italian national team) (Fig. 10a) and Carlo Ancelotti (one Italian Championship, two Champions League Cups and one Intercontinental Cup with AC Milan) (Fig. 10b).

In recent years, observers in the sector have carefully noted the work methodology of Josè Mourinho of Portugal, with whom Inter Milan was able to win the Italian Championship, the Italian Cup and the Champions League Cup during the single season 2009/2010.

Mourinho's innovation consists mainly in his training methods, defined as "tactical periodization". According to this approach, a coach/manager initially tries to instill in his players a set of potential intentions, that is, mental images of a specific type of game. Then, with each workout, he will try and bring into effect intentions that can suitably match the potential intentions, acting to reduce any discrepancy between the two.

Practically, this means that there is no distinction between physical, technical and mental training, since a player, once on the pitch, must use all his physical, technical and mental skills simultaneously and in an integrated fashion.

The approach known as the "Mourinho method" is often compared to the style of game applied by Joseph "Pep" Guardiola at Barcelona. During the season 2006-2007, at the helm of the club for only 3 years, Barcelona won 12 titles out of a possible 15 . The main methods introduced by the Catalan coach/manager can be distinguished into three distinct areas: technical-tactical, athletic and psychological. At a technical-tactical level, the game of Pep Guardiola recalls the total football of Rinus Michels, with an innovative twist on higher ball possession and pressing, that is taken to the limit of the adversary's area. The defensive and offensive lines are functional. The former involves remaining close to the midfield, the latter is formed by a wide, agile three-man attack that is always connected to the other lines, and involves continuous raid incursions into the penalty area ("cutting") while waiting for the ball from the midfielders. From an athletic prospective, Barcelona players are known for their running style, with short little quick steps, which, on the one side, gives them better control over the ball and its interception and, on the other, saves a lot of energy. Long and prolonged surges are avoided

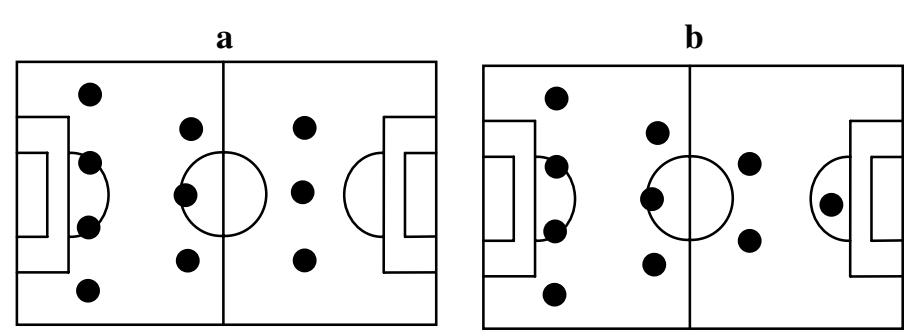

Fig. 10 a 4-3-3/Marcello Lippi and b 4-3-2-1/Carlo Ancelotti Source: Our elaboration 
since the Barcelona players are normally very close together in the field, and this prevents the onset of anaerobic metabolism and, therefore, going past the threshold beyond which an athlete begins to accumulate lactic acid and starts tiring. No less important than the technical-tactical and athletic aspects is the player's psychological training, based upon the objective of reducing unforeseen situations and containing emotion in the various phases of the game, by acting on "working memory", that is, on the player's operational unconscious.

\section{Discussion}

This brief examination of the history of ideas in the world of football consists in highlighting some particularly interesting aspects concerning the complex relationship between technical-tactical innovation and a team's wins.

First of all, it emerges that while not every win is based upon the assumption of innovation, the teams that have generated long-term winning cycles have often been able to combine their players' talent with innovative technical-tactical formations, managing to defend, for a certain period of time, their competitive advantage.

In the absence of legal methods to protect an innovative idea, it is useful to question the tools that have led to this defense, formulating concepts about the sustainability of competitive advantage in football teams.

Under a technical profile, some answers can be found in the context of the scientific model known as the resource-based view of a company (Barney 1986, 1991; Grant 1991; Peteraf 1993; Penrose 1959) according to which, the capacity of companies to gain a stable and sustainable competitive advantage is closely linked to their opportunities of exploiting their own distinctive skills.

According to the resource-based view, two properties determine whether competitive advantage is sustainable, the imperfect mobility of strategic resources and the presence of ex-post limits to competition.

With reference to the first property, Dierickx and Cool (1989) state that, in an organization, firm-specific resources (Becker 1964; Hashimoto 1981; Lazear 2003) are imperfectly mobile because they would lose part of their value if used in a different context from that in which they were created and accumulated.

In the football setting, this happens, for example, when players are only at ease when playing in a certain game formation.

Concerning the second property, Lippman and Rumelt (1982) coined the term "isolating mechanisms" to define the processes or variables that can be used to limit or hinder imitation on the part of competing companies. The tactical component of knowledge (Nonaka and Takeuchi 1995), an important category mentioned previously, can be considered as an integral part of the concept of isolating mechanisms.

Many of the changes introduced in football team formations are the result of a process of adapting to changes in the external environment, resulting from a variety of causes, among which, in particular, increased competition and the introduction of new game rules. There are, it is true, cases similar to technological discontinuity (Tushman and Anderson 1986), such as the introduction of Total Football, which led to substantial changes in the football environment, bringing on a period of great vibrancy that induced many teams to try and exploit the opportunities deriving from new trajectories. 
Winter (1987) observed that the more complex a skill is the lesser the risk of it being imitated. It follows that, by developing knowledge that is highly complex, there is a good chance that it will not be imitated, ensuring lasting competitive advantage for at least three types of reason. The first is linked to the difficulty of replicating operational procedures. The second to the difficulty in understanding which procedures are effectively capable of improving performance. The third is linked to the high complementarity with other elements in the system, so that there is no certainty that new procedures, once replicated, can provide the same level of performance in a different environment.

In light of the above, it is clear that not every technical-tactical innovation introduced by coaches/managers can be defended against attempts made by the competition to imitate them. Only innovation involving a complex set of competencies that are tightly integrated with other elements in the organization can lead to long-term competitive advantage.

\section{Conclusions}

Through this analysis, it is possible to state that technical-tactical innovation that can be considered a production process innovation or innovation in organization since they can generate competitive advantage for a football team generally derives from complex skills, closely knitted to the other elements defining the organization in its entirety.

Innovation is based upon a new management principle that puts into discussion a long-standing orthodoxy (the introduction of "Total Football" instead of the "Chain" approach). Innovation is systematic, in the sense that it embraces a range of processes or methods (Mourinho's tactical periodization). Innovation is part of a continuous programme of inventions in quick succession (the transition from the "WM system" to the "Chain").

If innovation becomes so radical, the coach/manager must be able to overcome the players' individual resistance to change and implement an innovation culture within the team, promoting eagerness, creativity and a sense of initiative in each member of the team.

In football teams, knowledge useful for solving problems is no longer concentrated at the summit, but can be widely spread within a group, which in turn becomes a virtuous team, and the members are highly qualified specialists with the right skills for each role within the team.

The practical implications deriving from the research show that distinctive innovation, such as technical-tactical innovation, can generate a competitive advantage, which, in the long term, results in economic return. This, in turn, can be transformed into lasting competitive economic advantage for teams where this type of innovation is implemented.

There are some limitations in the results of the research, the main being that only technical-tactical innovation was analyzed.

Research in the future will, therefore, expand the study to other types of innovation, to investigate which can generate greater competitive advantage for professional football clubs. 


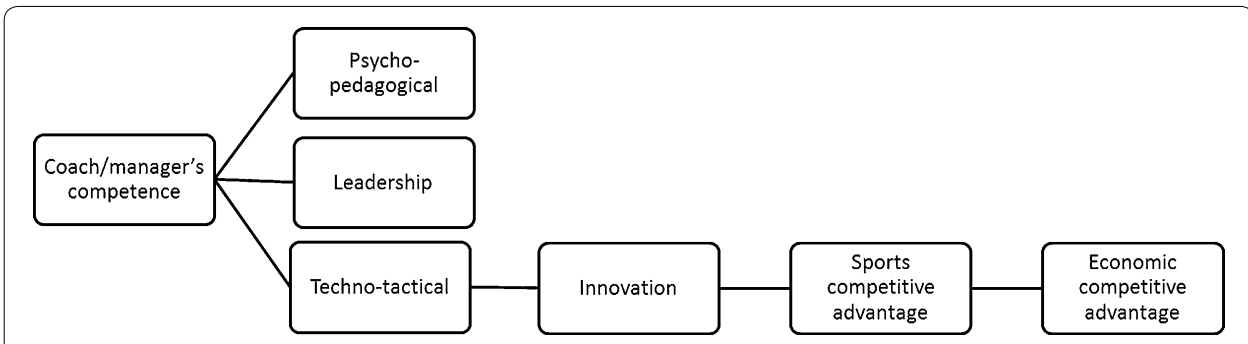

Fig. 11 Theoretical framework Source: Our elaboration

\section{Methods}

The research was carried out using a qualitative methodology (Maylor and Blackmon 2005; Myers 2013).

The theoretical framework was developed by initially focusing the analysis on the coaches/managers' set of skills, and in particular on their technical-tactical expertise. The reason why these technical-tactical skills were analyzed was to study their innovative role in creating a sports-related competitive advantage, and as a consequence, economic advantage for the professional football clubs where this innovation was implemented (Fig. 11).

A multi-case approach was used in the study (Eisenhardt 1989; Merriam 1998). The starting point of the research was the historical analysis of the main technical-tactical changes introduced in football, with their impact on football clubs and national teams. The purpose was to fill the gap in the literature in connection with the possibility of innovation in technical-tactical formations being a source of competitive advantage in the medium and longer term for football teams.

The research uses secondary sources (Yin 2013) and includes documents, reports, news items, journal articles in open sources, papers, scientific books and databases.

\section{Authors' contributions}

Although this article is the result of a group effort of analysis and reflection, RT authored "Conclusions" and "Methods" sections, MDL authored the "Background" section, BC authored the "The pyramid", "Metodo and WM system" and "Brazil and Italy" sections, and MP the "The revolution of total football", "Mourinho and Guardiola" and "Discussion" sections. All authors read and approved the final manuscript.

\section{Authors' information}

Raffaele Trequattrini is a Full Professor of Business Administration in the Department of Economics and Law at the University of Cassino and Southern Lazio in Italy, where he was appointed vice-chancellor. He had his Ph.D. in Business Administration at the University of Urbino. He was associate professor of Business Administration. His research interests cover the following topics: corporate governance, corporate disclosure, intellectual capital, accounting, knowledge economy, decision making, crisis of firms, business network and management of intangible assets. He has published refereed articles across a wide range of topics. In fact, he is author of articles and monographs regarding accounting, corporate governance, knowledge economy, business network and management of intangible assets. He serves as editorial board member and reviewer of international peer-reviewed academic journals. He is a member of the Research Committee on "Intellectual Capital" and Fellow EMAB at the EuroMed Research Business Institute. He is a member of the Accademia Italiana di Economia Aziendale (AIDEA) and Società Italiana di Ragioneria e di Economia Aziendale (SIDREA). He is the Scientific Coordinator of the LInC Laboratory of Intellectual Capital.

Manlio Del Giudice holds a Ph.D. in Management from the University of Milano Bicocca. He has active research collaborations with more than 20 universities across the globe, including many affiliations to celebrated universities and research centres, from New Zealand to United Arab Emirates. Prof. Del Giudice serves in the editorial board of many prestigious peer-reviewed academic journals. He is Associate Professor of Management at the University of Rome "Link Campus" and Professor of Management of the Biotech Firms at the "Federico II" University of Naples and he taught in a number of universities worldwide, including Grenoble Graduate School of Business, Twente University, Jonkoping University. Professor Del Giudice promoted and managed several academic spin off companies and technology transfer activities in the field of the green biotechnologies. He is consultant on project management for Government institutions in Italy, at national and regional level. His research interests deal with knowledge management, cross cultural management, family business management, entrepreneurship. 
Benedetta Cuozzo is a Ph.D. student in Business Administration in the Department of Economics and Law at the University of Cassino and Southern Lazio in Italy. Her research interests cover the following topics: business administration, intellectual capital and intellectual property rights, intellectual asset management and knowledge management, knowledge economy and management of intangible assets, decision making, and evaluation firms.

Matteo Palmaccio is a Ph.D. student in Business Administration in the Department of Economics and Law at the University of Cassino and Southern Lazio in Italy. He holds a Master Degree in Economics and Business Law (cum laude) at the University of Cassino and Southern Lazio during which he completed a period of study abroad in the LLP-Erasmus project. In the last academic year, he attended a Post-Graduate Advanced Course in Corporate Insolvency Law at the University of Rome "La Sapienza". His main research interests are corporate disclosure, intellectual capital, international accounting, corporate insolvency and business evaluation.

\section{Author details}

${ }^{1}$ Department of Economics and Law, University of Cassino and Southern Lazio, Via S. Angelo, Loc. Folcara, 03043, Cassino, FR, Italy. ${ }^{2}$ ESG Management School, Paris School of Business, 59 Rue Nationale, 75013 Paris, France.

\section{Competing interests}

The authors declare that they have no competing interests.

Received: 6 November 2015 Accepted: 8 June 2016

Published online: 04 July 2016

\section{References}

Anderson C, Sally D (2014) The numbers game: why everything you know about football is wrong. Penguin, London Barney JB (1986) Organizational culture: can it be a source of sustained competitive advantage? Acad Manag Rev 11(3):656-665

Barney JB (1991) Firm resources and sustained competitive advantage. J Manag 17(1):99-120

Baroncelli A, Lago U, Szymanski S (2004) II business del calcio. Egea, Milano

Bass BM (1985) Leadership and performance beyond expectations. Free Press, New York

Becker GS (1964) Human capital: a theoretical and empirical analysis, with special reference to education. University of Chicago Press, Chicago

Besen SM, Raskind LJ (1991) An introduction to the law and economics of intellectual property. J Econ Perspect 5(1):3-27

Bolchover D, Brady C (2007) II manager come allenatore. Gestire il team in azienda. Pearson, Italia, Milano

Borland J (2006) Production functions for sporting teams. In: AndreffW, Szyanski S (eds) Handbook on the economics of sport. Edward Elgar, Cheltenham

Bradford DL, Cohen AR (1984) Managing for excellence: the guide to developing high performance organizations. Wiley, New York

Carayannis EG, Campbell DF (2011) Open innovation diplomacy and a 21st century fractal research, education and innovation (FREIE) ecosystem: building on the quadruple and quintuple helix innovation concepts and the "mode 3 " knowledge production system. J Knowl Econ 2(3):327-372

Chesbrough H, Vanhaverbeke W, West J (eds) (2006) Open innovation: researching a new paradigm. Oxford University Press, New York

Collins M, Lovell MR, Iverson GL, Ide T, Maroon J (2006) Examining concussion rates and return to play in high school football players wearing newer helmet technology: a three-year prospective cohort study. Neurosurgery 58(2):275-286

Cottier T, Panizzon M (2004) Legal perspectives on traditional knowledge: the case for intellectual property protection. J Int Econ Law 7(2):371-399

Del Giudice M, Maggioni V (2014) Managerial practices and operative directions of knowledge management within inter-firm networks: a global view. J Knowl Manag 18(5):841-846

Dewar RD, Dutton JE (1986) The adoption of radical and incremental innovations: an empirical analysis. Manag Sci 32(11):1422-1433

Dierickx I, Cool K (1989) Asset stock accumulation and sustainability of competitive advantage. Manag Sci 12(35):1504-1511

Dyson B, Griffin LL, Hastie P (2004) Sport education, tactical games, and cooperative learning: theoretical and pedagogical considerations. Quest 56(2):226-240

Egbu CO (2004) Managing knowledge and intellectual capital for improved organizational innovations in the construction industry: an examination of critical success factors. Eng Constr Archit Manag 11(5):301-315

Eisenhardt KM (1989) Building theories from case study research. Acad Manag Rev 14(4):532-550

Grant RM (1991) The resourced—based theory of competitive advantage: implications for strategy formulation. Calif Manag Rev. doi:10.2307/41166664

Hashimoto M (1981) Firm-specific human capital as a shared investment. Am Econ Rev 71(3):475-482

Katzenbach JR, Smith DK (2005) The discipline of teams. Harv Bus Rev 83(7):162

Lazear EP (2003), "Firm-specific human capital: a skill-weights approach", in National Bureau of Economic Research, (No. W9679)

Liebermann DG, Katz L, Hughes MD, Bartlett RM, McClements J, Franks IM (2002) Advances in the application of information technology to sport performance. J Sports Sci 20(10):755-769

Lippman S, Rumelt R (1982) Uncertain imitability: an analysis of interfirm differences in efficiency ender competition. Bell J Econ 13(2):418-438 
Lombardi R, Trequattrini R, Battista M (2014) Systematic errors in decision making processes: the case of the Italian Serie A football championship. Int J Appl Decis Sci 7(3):239-254

Marshall A (1920) Principles of economics. Macmillan for the Royal Economic Society, New York

Maylor H, Blackmon K (2005) Researching business and management: a roadmap for success. Palgrave Macmillan, New York

Merriam SB (1998) Qualitative research and case study applications in education. In: Revised and expanded from " Case study research in education". Jossey-Bass Publishers, San Francisco

Myers MD (2013) Qualitative research in business \& management. Sage, London

Nonaka I, Takeuchi H (1995) The knowledge-creating company: How Japanese companies create the dynamics of innovation. Oxford University Press, Oxford

Penrose E (1959) The theory of growth of the firm. Oxford University Press, New York

Peteraf MA (1993) The cornerstones of competitive advantage: a resource-based view. Strateg Manag J 14(3):179-191

Rosen S (1981) The economics of superstars. Am Econ Rev 71(5):845-858

Schumpeter JA (1934) The theory of economic development: An inquiry into profits, capital, credit, interest and the business cycle. Harvard University Press, Cambridge

Schumpeter JA (1942) Capitalism, socialism and democracy. Harper \& Brothers, New York

Shah S (2000) Sources and patterns of innovation in a consumer products field: innovations in sporting equipment. Sloan Working Paper, Cambridge

Simonton DK (1999) Origins of genius: Darwinian perspectives on creativity. Oxford University Press, New York

Soto-Acosta P, Casado-Lumbreras C, Cabezas-Isla F (2010) Shaping human capital in software development teams: the case of mentoring enabled by semantics. IET Softw 4(6):445-452

Stone P, Balch T, Kraetzschmar G (2001) RoboCup 2000: Robot Soccer World Cup IV, vol 2019. Springer Science \& Business Media, Berlin

Trequattrini R, Lardo A, Cuozzo B (2015) Intellectual capital and management control systems: an application on professional football clubs. In: Spender JC, Schiuma G, Albino V(ed) 10th international forum on knowledge assets dynamics (ifkad) culture, innovation and entrepreneurship: connecting the knowledge. Bari, June 10th-12nd, 2015, ISSN 2280-787X, ISBN 978-88-96687-07-9

Tushman ML, Anderson P (1986) Technological discontinuities and organizational environments. Adm Sci Q 31(3):439-465

Wilson J (2010) Inverting the pyramid: the history of football tactics. Hachette, Paris

Winter SG (1987) Knowledge and competence as strategic assets. In: Teece DJ (ed) The competitive challenge. Ballinger, Cambridge

Yin RK (2013) Case study research: design and methods, 5th edn. SAGE Publication Inc, Thousand Oaks

\section{Submit your manuscript to a SpringerOpen ${ }^{\circ}$ journal and benefit from:}

- Convenient online submission

- Rigorous peer review

- Immediate publication on acceptance

- Open access: articles freely available online

- High visibility within the field

- Retaining the copyright to your article

Submit your next manuscript at $>$ springeropen.com 